\title{
THE INDEPENDENT ACTIONS OF TRAINEE NURSES DURING THE PRE-GRADUATION TRAINEESHIP
}

\author{
S. Dragusheva ${ }^{1}$, P. Petleshkova ${ }^{2}$, P. Kasnakova ${ }^{3}$, M. Mavrov ${ }^{4}$ \\ ${ }^{1}$ Department of Nursing Care; Faculty of Public Health Medical University - Plovdiv, Plovdiv, \\ Bulgaria \\ ${ }^{2}$ Department Obstetrics and Gynaecology, Medical Faculty, Medical University - Plovdiv, Plovdiv, \\ Bulgaria \\ ${ }^{3}$ Medical College; Medical University - Plovdiv, Plovdiv, Bulgaria \\ ${ }^{4}$ Department of Health Care Management, Faculty of Public Health, Medical University - Plovdiv, \\ Plovdiv, Bulgaria
}

\begin{abstract}
Introduction: The independent actions of students is the main method of work during the pregraduation traineeship. This is the reason why the pre-graduation traineeship demands high responsibility, independence and adaptability of trainee nurses. Students' independent actions are one of the most important components of the pre-graduation traineeship.

Objective: The aim of this study is to analyse the significance of students' independent actions as an indicator of the rising level of knowledge, skills and habits necessary for the professional development of the future nurses during the pre-graduation traineeship.

Materials and Methods: Two groups of respondents were surveyed: Students at Medical UniversityPlovdiv, Trakia University - St. Zagora-MF, Branch-Haskovo; University "Prof. Dr. Assen Zlatarov"Bourgas and mentors from the educational bases at the University Hospital "St. Georgi"- Plovdiv, Multiprofile Hospital for Active Treatment-JSC-Haskovo, University Hospital "Dr At. Dafovski"Kardzhali.

Results: According to all the trainees who took part in the study, the best conditions for independent actions are available during the pre-graduate traineeship. In this way students work on a schedule, and under the guidance of the mentor they do different activities independently and / or under control of the mentor. Trainee nurses are assigned independent actions according to their knowledge and skills and the specifics of the sector. As a result of the independent actions trainees acquire orientation skills in complicated practical situations and apply the gained knowledge in their independent practical activity.

Conclusion: The analysis makes clear that the organization of the trainee's independent actions is a factor for the optimization of the pre-graduation traineeship.
\end{abstract}

Key words: independent actions, trainee nurses, pre-graduation traineeship, knowledge, skills, habits, competences.

\section{INTRODUCTION}

Defining the profession of a nurse as humane, creative and risky sets the parameters of the programmes for creative improvement and spiritual growth of the student nurses and sets new challenges to their lecturers and tutors.

The main working method during the pregraduation traineeship is the students'

\footnotetext{
*Correspondence to: Snezana Dragusheva, Department of Nursing Care; Faculty of Public Health Medical University - Plovdiv, Bul. Vasil Aprilov 15-A, Plovdiv 4002, +359 887 204, sdragusheva68@gmail.com
}

independent work and its duration in the various sectors differs in work days and astronomical hours. Therefore, completing a pre-graduation traineeship requires high levels of responsibility, self-sufficiency and adaptivity from the trainee nurses.

The independent work of the students is one of the most essential components for the completion of the pre-graduation traineeship. It is a mandatory component of the education of the future specialists regardless of the fact that its status as a pedagogical category is still not entirely clear. Some authors claim that it is a method of education (G.Walter, A. I. Bushley), 
DRAGUSHEVA S., et al.

some call it a tool (A.V. Usova), and some call it an educational form (B. P. Esipov, A. G. Molibog). When the independent work is to be fully defined, according to P. Petrov, it is to be defined first and foremost as a special kind of activity (P. Petrov, 1998:415). (1)

We speak of working independently, usually when the student works alone, without a tutor. This on its own, however, is not enough. Independent work is carried out when the trainees are presented with the opportunity to look for solutions to the set tasks on their own, or to themselves raise issues and find the most rational solutions to the problems. Therefore, they can demonstrate real independence only in the action they complete without the immediate participation of their tutor or another person, using their personal experience and the already mastered knowledge and skills. Even though independent work has a controversial status in the system of didactic categories, it remains a significant fact, and it is impossible to think about modern education without it.

Students do this type of work without the direct interference of their instructor, relying on their knowledge, skills and habits, but with a specific educational purpose defined by the professor/mentor. This work has its organisation, it is done using various methods and tools within or outside of the mainframe of the basic organisational form of education and is compliant to the primary problems that educational forms solve.

Therefore, the independent work of the students is a learning activity consciously performed by them without the immediate participation of the instructor and in compliance with a specific didactic purpose (M. Mitova, S. Mladenova, 2008). (2)

During the pre-graduation traineeship, independent work is done in the medical facility/establishment without the presence of the tutor. That is why it has to be very well organised, monitored and assessed based on content, volume, scope and difficulty. The mentor strictly follows, facilitates and assesses the independent work of the future nurses.

The problem of the classification of the students' independent work is a complicated one, much like the issue of its essence. That is why there is no single classification of independent work.

The approaches to the classification of working independently are too diversified, and currently there is no universal classification in the pedagogical publications and didactics books. In spite of that, there is a preference for classification in accordance with the educational purpose:

- independent work to prepare students for learning new material;

- working independently to learn new material;

- working independently to consolidate, expand and improve the acquired knowledge;

- working independently in order to develop, establish and improve skills and habits.

because it is practically more convenient and does not lead to mixing the signs of the different kinds of independent work. (M. Andreev, 1996:370-371). (3)

To be able to work independently during the pre-graduation traineeship the following conditions must be present:

- A set time limit for the independent work of the students;

It is appropriate to have a differentiated approach that has to take under account the specific conditions and requirements of the relevant sector.

- Material and technical facility for education and independent work- Practice shows that working independently can be used efficiently in the process of preparation of the students only when a satisfactory material and technical facility is provided.

- Planning independent work- the efficiency of working remotely for the students depends on its appropriate planning.

Independent work needs operational control and guidance on the part of the mentor so that its cognitive capabilities can be utilised in order for it to contribute to the overall improvement of the student. The independent work of the students in the medical institutions of higher education is distinguished by its own features and specific qualities. Depending on the educational purpose it can be related to obtaining new skills, habits or knowledg,e or with improving and building on those already acquired in order to increase the level of comprehension.

It should be borne in mind that there is a certain level of risk in organising and and conducting independent work in hospitals as students are forced to form behavioural patterns before they have mastered sufficient theoretical knowledge and practical skills and habits. Undoubtedly, working independently is focused on achieving a certain goal and it has to be individual and differentiated in 
accordance with the level of education of the students.

The independent work of the students is characterised by a great variety in content and type, and it finds its broadest implementation during clinical practice and especially in pregraduation traineeship.

The purpose of this study is to analyse the significance of independent work as an indicator of enhancement and improvement of the knowledge, skills and habits necessary for the professional career of the future nurses during pre-graduation traineeship.

\section{MATERIAL AND METHODS}

The opinions of two groups of respondents were analysed: Nursing students from MUPlovdiv, Faculty of Public Health; Trakia University- Stara Zagora- Medical faculty and the Haskovo affiliate; "Professor Doctor Assen Zlatarov" University- Burgas and mentors from university clinics and hospitals - UMBAL "Sv. Georgi"- Plovdiv, MBAL-AD-Haskovo, MBAL "Dr. At. Dafovski”- Kardhzali

\section{RESULTS}

It was important for us to survey the opinion of the respondents on the forms of education which provide the best conditions for independent work. According to all trainees taking part in the research, pre-graduation traineeships provide the best conditions $(99,2 \%)$. During their traineeship students work according to normal schedules along with their mentor, and under their mentor's guidance they perform various activities either independently or under supervision. Trainee nurses are given individual tasks in accordance with their skills and knowledge and in compliance with the specificities of the sector/ward. Clinical practice is ranked second (78.9\%) and practical exercises (tutorials) third at $36.2 \%$. Seminars were mentioned by only $13.6 \%$ of all respondents because of their theoretical nature and use of literary sources. No statistically important differences between the responses of students from different educational facilities were established $\mathrm{P}>0.05$. The responses are predictable and show a realistic view of the opportunities for independent work of the future specialists (Figure 1).

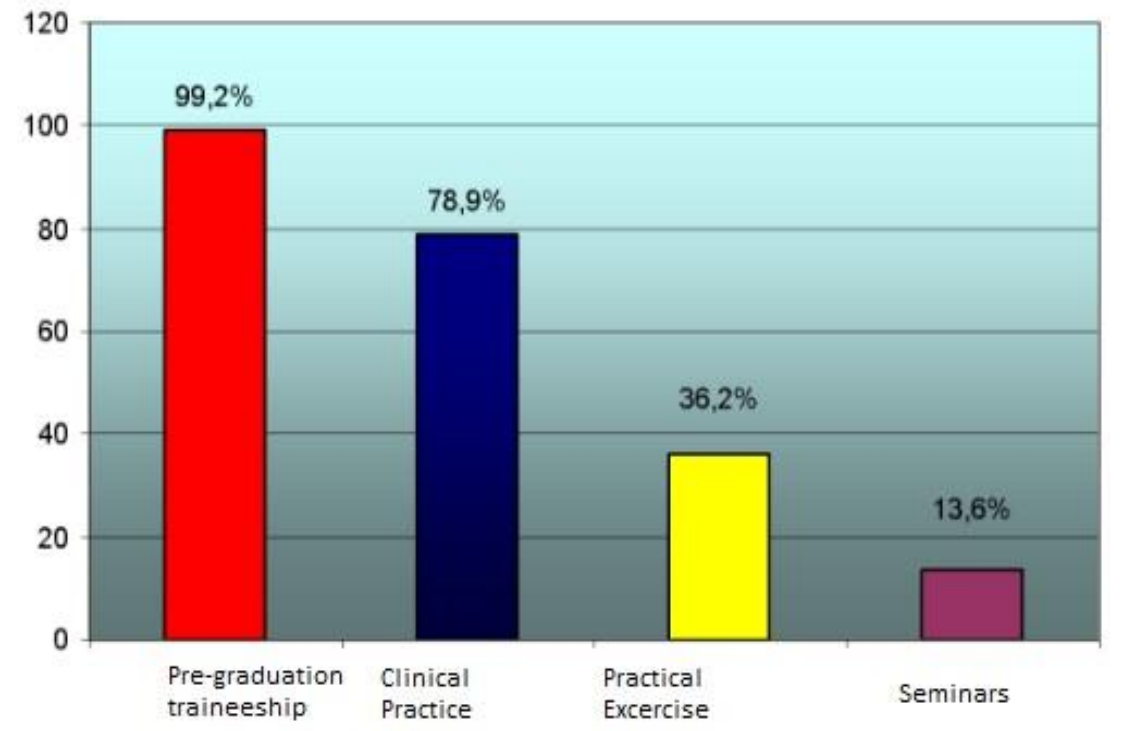

Figure 1. Educational and training forms that provide the best conditions to work independently

Working independently can be viewed as an opportunity for trainee nurses to improve their knowledge, to be self-sufficient; on the other hand, independent work can be considered a way to monitor and build on the acquired knowledge and mastered practical skills and habits. As a result of working independently, trainees form skills to navigate in complicated practical situations and to apply the mastered knowledge in their independent practical activity. It is in the process of individual independent work that the separates psychological processes and the overall personality of the medical specialist are developed.

In relation to the previous question, the answer given to the question "Do you feel confident when completing the set practical tasks?" is of particular interest. The highest percentage of the respondents (84\%) have answered"Yes", whereas only $4 \%$ gave a negative answer and $12 \%$ couldn't decide. These answers gives us reason to assume that the majority of the students have created a theoretical algorithm for a reaction in a real hospital situation which 
has a positive effect on the motivation of the students and the forming process. This result, in our opinion, is most likely the result of using
DRAGUSHEVA S., et al. teaching methods that stimulate the clinical creative thinking (Figure 2).

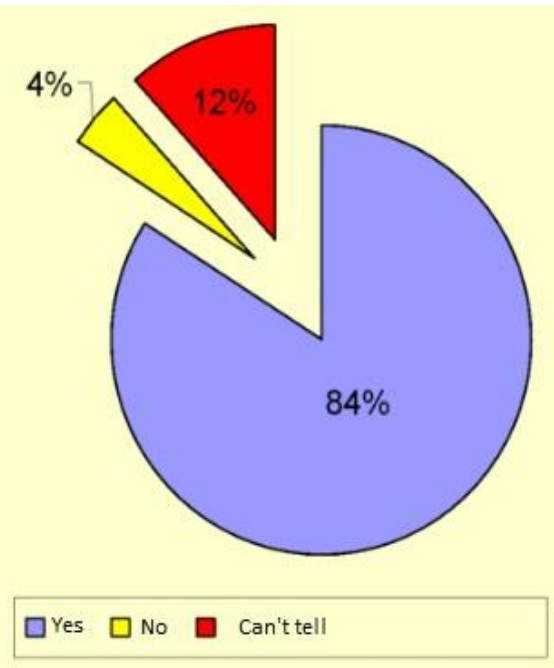

Figure 2. Confidence in completing practical tasks

The questionnaire included a question for both students and mentors about the skills that they need to obtain and master to automation and prioritise during the pre-graduation traineeship as a component of professional competence (Table 1).

Table 1. Skills to be improved during the pre-graduation traineeship

\begin{tabular}{|c|c|c|c|c|}
\hline Type of Activity & Trainee - nurses & Mentors & $\mathrm{U}$ & $\mathrm{P}$ \\
\hline Handling /operation/ skills & $98.08 \% \pm 0,93$ & $96.09 \% \pm 2,07$ & 0,88 & $>0,05$ \\
\hline $\begin{array}{c}\text { General nursing \& hygiene } \\
\text { skills }\end{array}$ & $88.08 \% \pm 2,20$ & $41,63 \% \pm 5,25$ & 8,16 & $<0,001$ \\
\hline $\begin{array}{c}\text { Administrative skills / } \\
\text { working with medical } \\
\text { documentation, recording } \\
\text { indicators/ }\end{array}$ & $70.38 \% \pm 3,10$ & $19.84 \% \pm 4,25$ & 9,61 & $<0.001$ \\
\hline $\begin{array}{c}\text { Communication skills at a } \\
\text { horizontal and vertical level }\end{array}$ & $80.77 \% \pm 2,68$ & $57.03 \% \pm 5,28$ & 4,00 & $<0.001$ \\
\hline $\begin{array}{c}\text { Skills for preparing nursing } \\
\text { care plans }\end{array}$ & $56.54 \% \pm 3,37$ & $47.66 \% \pm 5,32$ & 1,41 & $>0,05$ \\
\hline $\begin{array}{c}\text { Skills for providing special } \\
\text { care, according to the diseases } \\
\text { in the respective ward }\end{array}$ & $40.00 \% \pm 3,33$ & $52.56 \% \pm 5,33$ & 2,00 & $<0,05$ \\
\hline $\begin{array}{c}\text { Preparation and participation } \\
\text { in examinations and tests of } \\
\text { the different organs and } \\
\text { systems }\end{array}$ & $55.77 \% \pm 3,37$ & $60.94 \% \pm 5,2$ & 0,83 & $>0,05$ \\
\hline
\end{tabular}

As regards mastering operational skills, there is a high percentage (over 96\%) in both groups of respondents.

A statistically significant difference is observed in the choice of "Skills for providing general nursing and hygiene care" $\mathrm{P}<0.001$. The percentage of trainee-nurses making this choice $(88 \%)$ is quite high, unlike the respective percentage of mentors $(42 \%)$, which is relatively low.
A statistically significant difference is also observed as regards the choice of "Administrative skills / working with medical documentation" $\mathrm{P}<0.001$. Again the percentage of students making this choice is considerably higher $(70.38 \%)$ as compared to the relatively low percentage of mentors $(19.84 \%)$.

Another statistically significant difference is observed in the choice of "Communication skills at horizontal and vertical level" $\mathrm{P}<0.001$. The percentage of students who have given 
DRAGUSHEVA S., et al.

priority to that skill $(81 \%)$ is higher than that of mentors (57\%) who have given priority to the same skill.

In the priority the surveyed give to "Skills for providing special care in accordance with the diseases in the respective ward", there is also a considerable difference $\mathrm{P}<0.05$. Mentors believe it is necessary to pay greater attention to the development of these skills (Table 1).

All surveyed groups give a moderately high priority to "Preparing nursing care plans" and "Preparation and participation in examinations and tests of the different organs and systems" $(\mathrm{P}>0.05)$.

It is of note that most respondents evaluate fairly highly the significance of these skills for the development of professional competences of medical specialists. It appears, however, that mentors tend to underestimate most skills.

One of the most important purposes of the pregraduation traineeship is the mastering of operational skills to the highest level - so that they become virtually automatic.

As demonstrated by the responses to the previous question, this activity is given the greatest priority by both students and mentors. The findings show that $72.8 \%$ of the traineenurses are most confident when performing intramuscular and subcutaneous injections $\mathrm{P}<0.01$, whereas there is not difference in their confidence when performing the other two manipulations $\mathrm{P}>0.05$.

Students have provided more than one answer (Table 2).

Table 2. Confidence when performing manipulations

\begin{tabular}{|c|c|c|c|c|}
\hline Manipulations & Number & $\mathbf{\%} \pm$ Sp & U & P \\
\cline { 1 - 3 } Subcutaneous & 174 & $61,5 \pm 2,89$ & \multirow{2}{*}{2,86} & $<0,01$ \\
\hline Intramuscular & 206 & $72,8 \pm 2,69$ & & \multirow{2}{*}{0,93} \\
\cline { 1 - 3 } Intravenous & 167 & $59 \pm 2,92$ & $>0,05$ \\
\hline Infusion & 156 & $55,1 \pm 3,0$ & & \\
\hline
\end{tabular}

It is an interesting fact that trainee-nurses report encountering no difficulties when performing most manipulations, which proves that their practical training and their pregraduation traineeship (as part of their overall practical training) truly contribute to the development of their professional competences. The lower percentage of students feeling confident when performing intravenous manipulations and infusions $-59 \pm 2,92 \%$ and $55,1 \pm 3,0 \%$, respectively - is a signal to instructors that they should motivate, encourage and support students to overcome their fear of these manipulations during their practical training and clinical practice. Furthermore, many emergencies require intravenous manipulations most of all.

According to the surveyed students (72\%), working in real hospital conditions entails risks to their health. Nearly one third of the students $-31.3 \%$ - believe such risks to be quite high, and this has a negative impact on their level of satisfaction with the pre-graduation traineeships; $24.5 \%$ feel completely dissatisfied with this fact; and $50.0 \%$ report being dissatisfied to an extent. In the hospital ward they come face to face with suffering and death, with the experiences of the patients and their families, and this is an emotional strain for students. A moderate interdependence was established between the conditions of the pre- graduation traineeship and the level of satisfaction of the students. The greater the risks to their health, the lower the level of their satisfaction with their training $\mathrm{P}<0.01 \quad(\mathrm{r}=$ 0.48). (Figure 3)

The repeated performance of manipulations creates the impression on students of monotony of the activities $(1,91 \pm 0,09)$ as a feature of the pre-graduation traineeship. A considerable dependence is observed between the level of student satisfaction and the monotony of the performed tasks $\mathrm{P}<0,01(\mathrm{r}=$ $0,56)$. In this regard, it is necessary that tutors and mentors should involve students in various activities every day during their pre-graduation traineeship (Figure 3).

In the real conditions of the medical practice, future registered nurses demonstrate spontaneous interest and master functional activities, patterns of professional conduct and of decision-making. In the training of nurses, the main focus is on the patient and his/her family. The respondents state they have the opportunity to make independent decisions $(3,00 \pm 0,09)$ and they find it satisfying and rewarding to a great extent $\mathrm{P}<0,001(\mathrm{r}=0,74)$. On the other hand, $77,8 \%$ of the students claim that when performing activities in real practice, they are constantly under great time pressure $(3,21 \pm 0,09) .39,1 \%$ of the respondents find it 
extremely dissatisfying $(1,74 \pm 0,1)$. The greater the lack of time for accomplishing activities during the pre-graduation traineeship, the higher the level of student dissatisfaction $\mathrm{P}<0,001 \quad(\mathrm{r}=-0,72)$. This should alert mentors
DRAGUSHEVA S., et al. and tutors that an organization of work should be developed in such a way as to enable the balanced distribution of the performed activities.

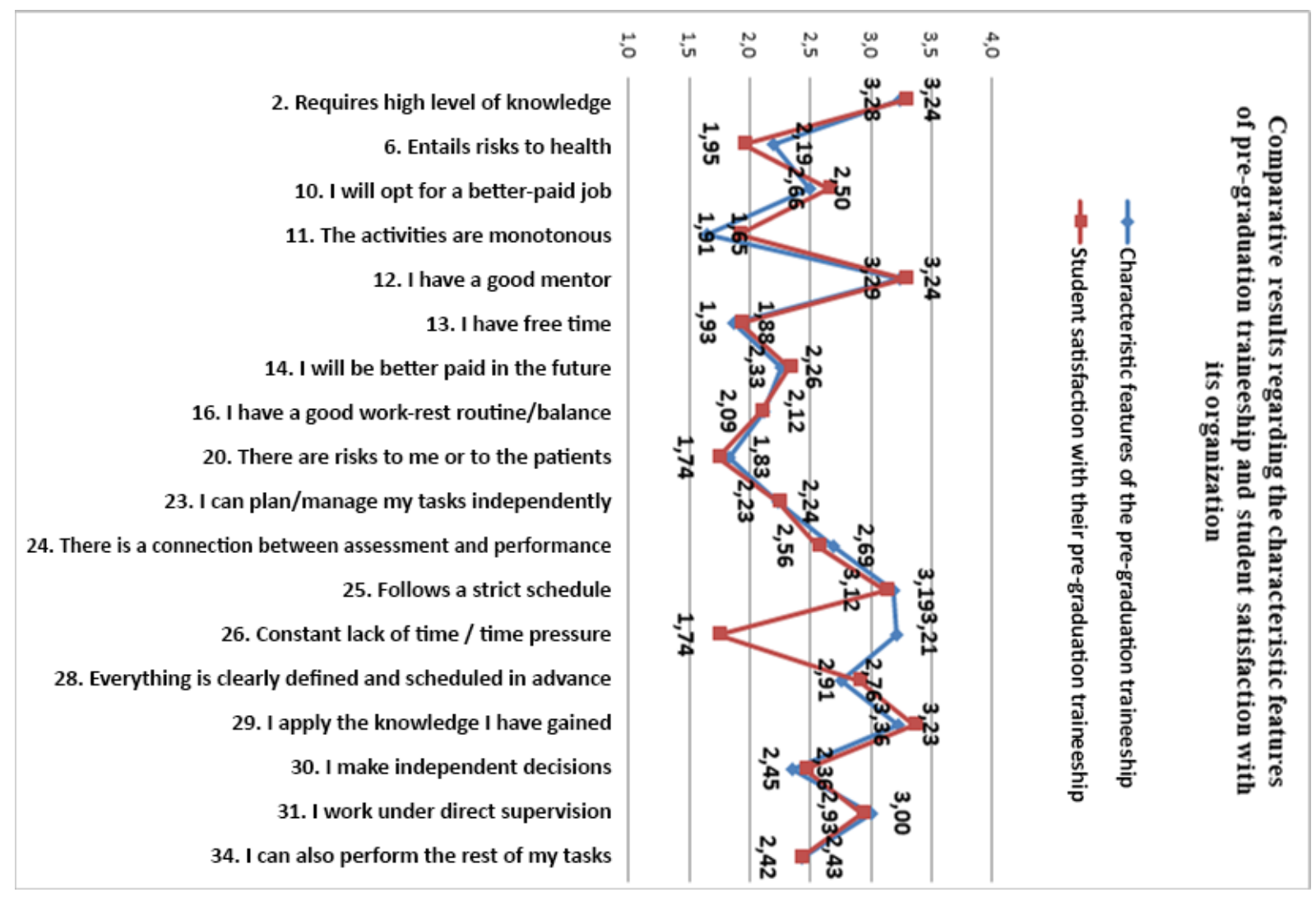

Figure 3. Characteristics of the pre-graduation traineeship and level of student satisfaction with the organization and educational value of the pre-graduation traineeship

The summarized analysis of the results of the survey leads to the following conclusions:

Students' independent work during their pregraduation traineeship is a major factor for:

- Enhancing the level of knowledge mastered;

- Developing professional skills and competences;

- Improving practical skills to perfection and providing independent nursing care, necessary for students' professional fulfillment and career;

- Ensuring sufficient activities performed by trainee-nurses independently.

\section{CONCLUSION}

It is evident from the analysis made that the independent work of the trainee-nurse is an important factor in the optimization of the pre- graduation traineeship. It creates conditions for developing self-dependence as a characteristic feature of the would-be registered nurses, for developing flexible skills and competences, as well as personal qualities that are of great significance for the profession and abilities to perform one's job duties independently in the context of the provision of quality care of the patient - healthy or sick.

\section{REFERENCES}

1. Petrov P., Didactics, published by 'VedaSlovena J.G.', Sofia,415, 1998

2. Mitova M., Mladenova S., 'Methods of Practical Training of Healthcare Specialists', Sofia, Artic-2001;7-9,85,8889, 2008.

3. Andreev M. Didactics, Sofia,364, 1993 